\title{
Impacts of Network Efficiency on Number of Customers - A GIS Perspective: Study of Telecom Industry in Karachi
}

\section{Nasir Khan*}

Department of Geography, University of Karachi, Pakistan

\begin{abstract}
The efficiency of utility networks played an important role to attract the new customers and to attach the existing customers with the services. Utility services may belong to provide electricity services, telecommunication, gas supply etc. In telecommunication industry, network elements that installed in ground having direct impact on the number of customers. Pakistan Telecommunication Company Limited (PTCL) is not only the giant telecom service provider and backbone of country's telecommunication infrastructure but also it played an important role in the economy of the country. It has the largest fixed line network but due to many reasons a large number of customers are shifted from landline connections to other cellular services. From this study it is concluded that approximate $60 \%$ network elements have bad, $19 \%$ network elements have an average jumpering status within the installed units. As far as physical status is concerned $40 \%$ of the network elements have bad physical condition means that the unit becomes rusty or damaged. All such factors are responsible to create noise or cross talking in the landline connection that results the reducing number of customers. GIS is an effective tool which is being used throughout the world to monitor the efficiency of installed network that's why intelligent maps are developed in this study through GIS techniques to point out the affected areas.
\end{abstract}

Keywords: Customers; GIS; Installed networks; Telecommunication

\section{Introduction}

Telecommunication is a major component of the communication industry. Telecommunication conducted over wired and wireless facilities that link every home and business not only in Pakistan but also around the globe. The technology of telecommunication increasingly involves broadband networks based on optical fiber with ever increasing capacity and controlled by programmable computers offering considerable flexibility in features. Wireless technology enable people to stay in touch wherever and whenever they desire over great geographic areas. The telecommunication industry in Pakistan has grown tremendously. Pakistan Telecommunication Company Limited (PTCL) is the largest telecommunication company in Pakistan. This company provides telephony services to the nation and still holds the status of backbone for country's telecommunication infrastructure. The company consists of around 2,000 telephone exchanges across the country providing largest fixed line network. GSM, CDMA, Broadband Internet, IPTV and EVO are other major resources of PTCL, making it a gigantic organization.

\section{The Problem}

PTCL was one of the best telecom service providers in Asia and had a number of technical experts and engineers who got opportunity to work in foreign countries and help them to install the telecom networks. PTCL was the first who had introduced an extensive optical fiber and copper network.

Besides the fact that PTCL had huge landline network, its customers had been falling tremendously. Keeping in view the competition in telecommunication sector and to fulfill the requirement of its customers, PTCL had introduced new services especially wireless broadband service to its valued customers. It provided unified tariff for on net calls to retain the customers but it was taking much time to regain its valued customers. There was a need to find the factors that impacted on the efficiency of installed network and are responsible for reducing number of customers.
Figure 1 clearly shows that there were 5,190,899 customers in 2005 while in 2010 there were only 3,268,642 landline customers in PTCL. There was a drastic decline of 1,922,257 customers in five years.

GIS techniques are used in this study to identify the factors that are affecting the number of customers. GIS and cartography have traditionally been regarded as fields for the study of techniques [1]. GIS is an advanced technology that uses an analytic framework for solving various geographic problems and for integration of multiple databases. It plays an important role to analyze current and predict future situations. Interest in commercial application of spatial interaction model was more obvious in 1980s and early 1990s for a number of reasons [2]. Geographically referenced information can be store, integrate, query, analyze and display in the form of intelligent maps with the help of GIS. GIS enables to create and manage spatial data and its attributes. In other sense we can say that GIS is a powerful tool which helps to handle and analyze spatial data for decision making.

GIS applications in telecommunication include multiple market and demographic analysis, target marketing customer segments for communication products and optimal site locations for cables and cellular towers. GIS technology enables telecommunication companies to integrate geospatial data with other data such as customers, operations and marketing for planning and problem solving purposes. Many local and long distance telephone companies use GIS to monitor, evaluate and analyze network performance and problems. According to Bidgoli [3] GIS technology enables telecommunication professionals to

*Corresponding author: Nasir Khan, Department of Geography, University of Karachi, Pakistan, Tel: 9221 99261300; E-mail: nasirkhangis@gmail.com

Received September 07, 2017; Accepted October 03, 2017; Published October 11,2017

Citation: Khan N (2017) Impacts of Network Efficiency on Number of Customers - A GIS Perspective: Study of Telecom Industry in Karachi. J Telecommun Syst Manage 6: 154. doi: 10.4172/2167-0919.1000154

Copyright: (c) 2017 Khan N. This is an open-access article distributed under the terms of the Creative Commons Attribution License, which permits unrestricted use, distribution, and reproduction in any medium, provided the original author and source are credited. 


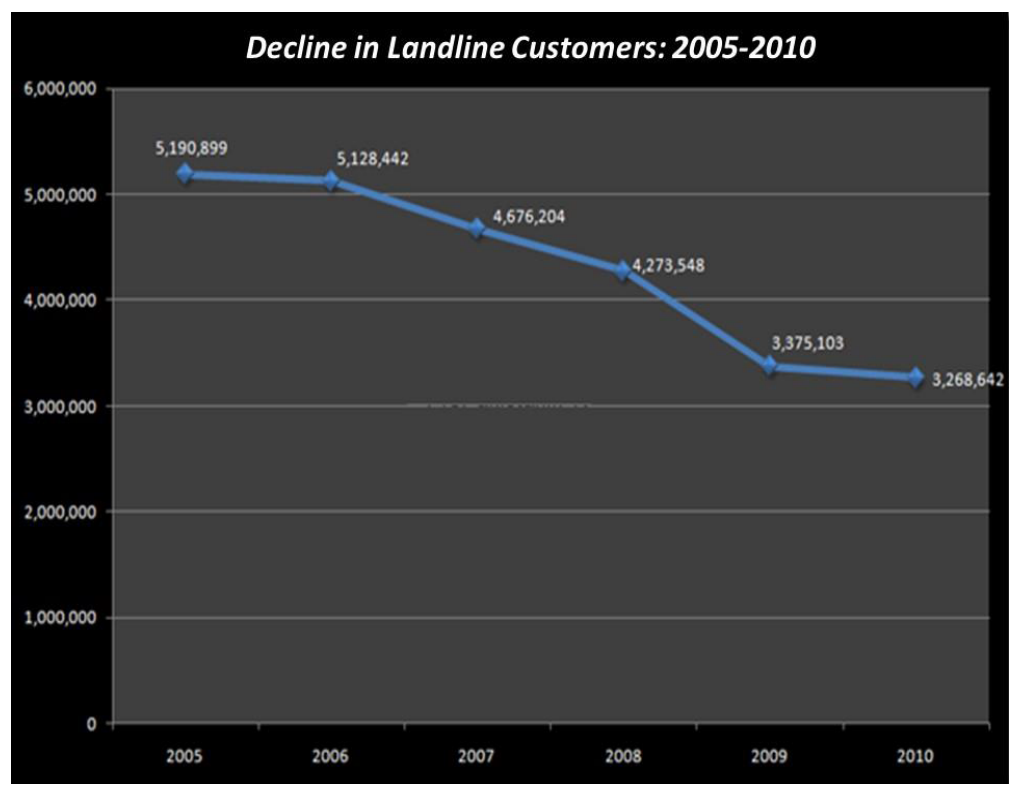

Figure 1: PTCL landline customers during 2005-2010. Source: Attaa [6].

integrate location based data into analysis and management processes in network planning and operations, marketing and sales, customer care, data management and many other problem solving tasks. A GIS can integrate location-based data from databases all over the world to help in resolving and streamlining everyday business issues [4].

\section{Objectives}

The main objective of the study is to analyze the factors affecting the efficiency of installed network elements that caused reducing number of customers.

Some following specific tasks have to be done to achieve the main objective successfully:

1. To identify and analyze the geographic location of different Exchanges within the study area.

2. To demarcate the covered area of each telephone exchange.

3. To identify the installed network elements within each exchange boundary.

4. To analyze the increasing or decreasing number of customers.

Study area (AOI): Karachi is the largest city of Pakistan having an estimated twenty three million people. Pakistan Telecommunication Company Limited has divided the whole city into three telecom regions. Study is conducted in the second largest telecom region of the city which includes fourteen telecom exchanges and having capacity of $3,97,760$ subscribers. Working connections within the region are $2,49,402$. The region comprises parts of eight towns of the city including New Karachi, Nazimabad, Orangi, Gulshan-e-Iqbal, SITE and Baldia Town. There is variation among the customer types as the region has different socio-economic conditions.

Pakistan Telecommunication Company Limited (PTCL) is the Pakistan's most reliable and largest converged services carrier which provides all telecommunications services from basic voice telephony to data, internet, video-conferencing and carrier services to consumers and businesses all over the country. Extensive developments are made for providing effective services to the valued customers and to increase the number of customers but besides all the developments this giant organization has been facing reducing number of customers.

\section{Methodology}

A framework is designed to accomplish the tasks successfully. Right from the very first stage i.e. the data collection to the final output following steps has been taken.

\section{Data collection}

The process of gathering information about a number of variables and ground realities for conducting research is known as data collection. In this research following two types of data has been collected.

\section{Primary data collection (GPS surveys)}

Primary data collection included GPS surveys and field data collection. In the first phase author conducted GPS surveys for identifying geographic locations of all telecom exchanges within the study area. In second phase GPS surveys conducted to mark the covered area of each telephone exchange and in the third phase all network elements that installed on ground are surveyed and their related information are gathered.

\section{Secondary data collection}

Secondary data is such type of data that have been already available from various sources. Secondary data has its own importance. It may be quickly obtainable from primary data. It helps to understand and target the problems effectively. Secondary data collection included satellite data acquisition, collection of old network maps, collection of active customers in each exchange and types of services provided to the customers.

\section{Survey data conversion and verification}

All GPS surveyed data is converted into GIS environment using GPX file that is supported in Arc GIS. Surveyed point are also imported in Google earth, free web ware software, for verification of captured points and to remove any error occurred during GPS surveys. 
Citation: Khan N (2017) Impacts of Network Efficiency on Number of Customers - A GIS Perspective: Study of Telecom Industry in Karachi. J Telecommun Syst Manage 6: 154. doi: 10.4172/2167-0919.1000154

Page 3 of 7

\section{Scanning and geo-referencing of maps}

The transformation of hard copy maps into digital form is known as the process of scanning. After scanning the scanned maps also known as raster maps but without registration of these rasters to some specific projection system it is useless. These maps are often referred to as "dumb maps"

Geo-referencing is a process of registration a raster in which we define actual coordinates or a physical space to each pixel of a raster. Three ground control points (GCPs) are needed to geo-reference a raster. All network maps that are available become geo-referenced by a number of GCPs to increase the accuracy of different network element's locations (e.g. junction cable route between different exchanges).

The author has projected the raster maps using UTM projection .i.e., Universal Transverse Marcater's Projection. In this projection there is very less distortion in measuring distance. The WGS84 ellipsoid is used to project the world into UTM coordinate system. As Karachi, Pakistan falls in zone 42 of UTM projection system therefore author used zone 42 to project entire datasets into UTM projection system.

Figure 2 shows the process of geo-referencing of raster data that is developed by using a number of tiles downloaded from google earth.

\section{Geo-database design}

Geodatabase is a container that can hold many datasets. Digital spatial databases consist of geometrical descriptions of entities, with their associated topological relationships and attributes [5]. Personal geodatabases, file geodatabases and ArcSDE geodatabases are three different types of databases. In this study author has used personal geodatabase to accomplish the task.

\section{Feature dataset}

As telecom network are digitized in point, line and polygon feature classes having same projection system therefore all these vector data are managed in feature dataset.

\section{Raster dataset}

Raster image that is created by downloading a number of tiles from a free webware i.e. google earth and managed this image in raster dataset.

\section{Digitization}

Digitization is the process of converting raster data into vector form i.e. in the form of point, line and polygon layers. The scale on which digitization has taken place is 1:1000 using satellite image of QuickBird. All telecom exchange boundaries and available junction routes are digitized as well as surveyed network elements are incorporated into GIS environment. Digitization errors are removed successfully to increase the accuracy of the geographic data.

\section{Populate the attributes}

A number of fields are added to attach the relevant data with every record of geographic data in point, line and polygon feature classes. The information that is collected against each telecom network from the concerned department is incorporated to its geographic location and displayed in the form of intelligent maps. The number of customers are also available for the year 2002 and 2012 which shows the clear trend of increasing and decreasing number of customers in each exchange.

\section{Results and Discussions}

The most important findings of this study are discussed here. All the factors that are responsible to reduce the number of customers are shown in the form intelligent maps so that the management would be able to take some necessary actions to get its valued customers back. This study is conducted on the data that is provided and collected during GPS surveys in 2012.

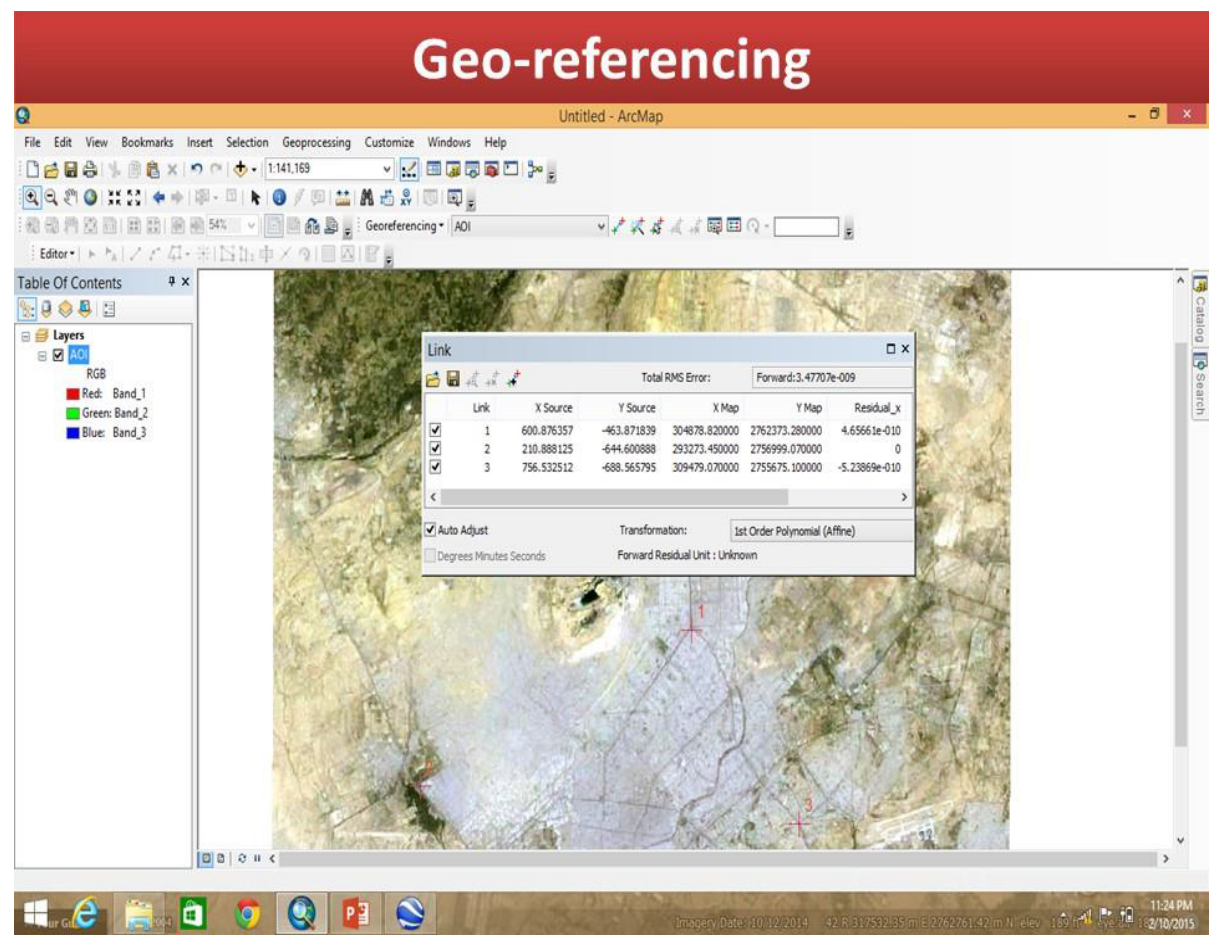

Figure 2: Geo-referencing of satellite image. Source: Author. 
Citation: Khan N (2017) Impacts of Network Efficiency on Number of Customers - A GIS Perspective: Study of Telecom Industry in Karachi. J Telecommun Syst Manage 6: 154. doi: 10.4172/2167-0919.1000154

Page 4 of 7

Figure 3 below shows that there are three telecom regions in Karachi. Each region has more than ten telecom exchanges covering different areas. KTR-III is the region in which study is conducted as it has variation in number of customers based on socio-economic conditions. This region has fourteen telecom exchanges.

Figure 4 shows that there are fourteen exchanges in the study area. This map is showing the geographic locations of all telecom exchanges that is captured after conducting GPS surveys.

Figure 5 shows the areas covered by each telephone exchange. All telephone exchange boundaries are marked after conducting GPS surveys and digitized on developed raster. Exchange area is calculated after digitization and marked in Table 1. It is also observed that each telecom exchange has the number and type of network elements that installed in 2002 and 2012. In 2002, there were 786 copper cabinets that were installed on ground where as in 2012, there were 986 installed network including copper cabinets and optical network units (ONUs).

Figure 6 is showing the geographic locations of copper cabinets and ONUs in 2002 and 2012. It is clearly observed that there is not a single ONU installed in 2002 whereas there are 200 ONUs installed till
2012 to enhance the efficiency of telecom network and to increase the number of customers.

Table 2 is showing a clear picture of declining number of customers in all exchanges except Ahsanabad, Gulshan-e-Maymar and New Sabzimandi exchanges. There were total 3, 74,793 landline customers in 2002 when installed network elements were 786 whereas the number of customers in 2012 were 2, 38,668 while having 986 installed network elements including copper and optic fiber networks.

Figure 7 is showing the geographic locations of all those network elements which are not in proper working order and responsible to interrupt the services which causes the reducing number of customers. This map shows that $0.4 \%$ of the total network elements that were damaged during extensive civil works is not rehabilitated, $0.5 \%$ of the total network is not attended due to law and order situation within the area. Similarly, $32.1 \%$ of the total installed network is in worst condition and having a number of problems in providing un-interrupted services to the customers. Besides having also an optical fiber network all these factors are responsible in reducing number of customers [6-8].

Table 3 is showing the jumpering and physical status of network elements that have installed within the study area. It is observed that

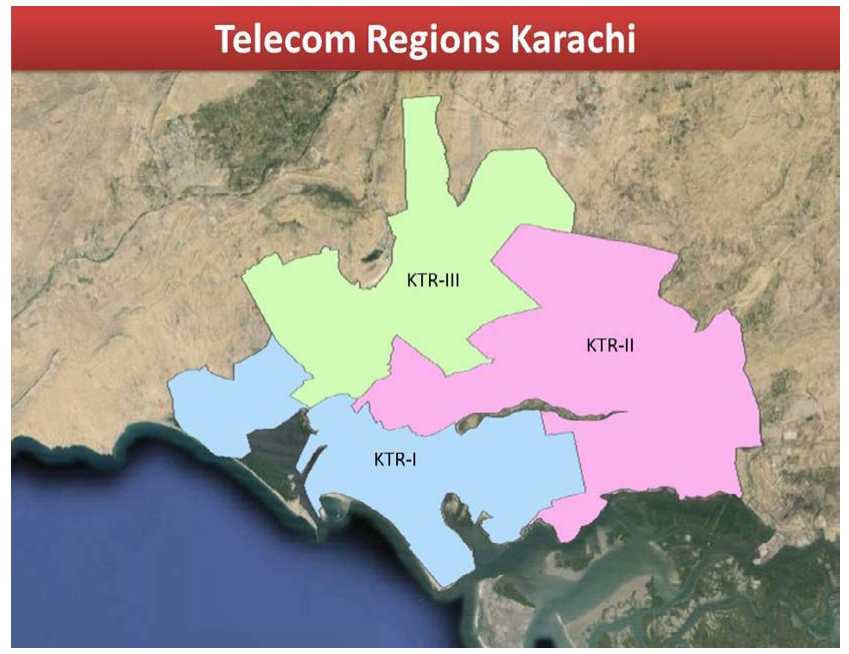

Figure 3: Karachi telecom regions. Source: Author.

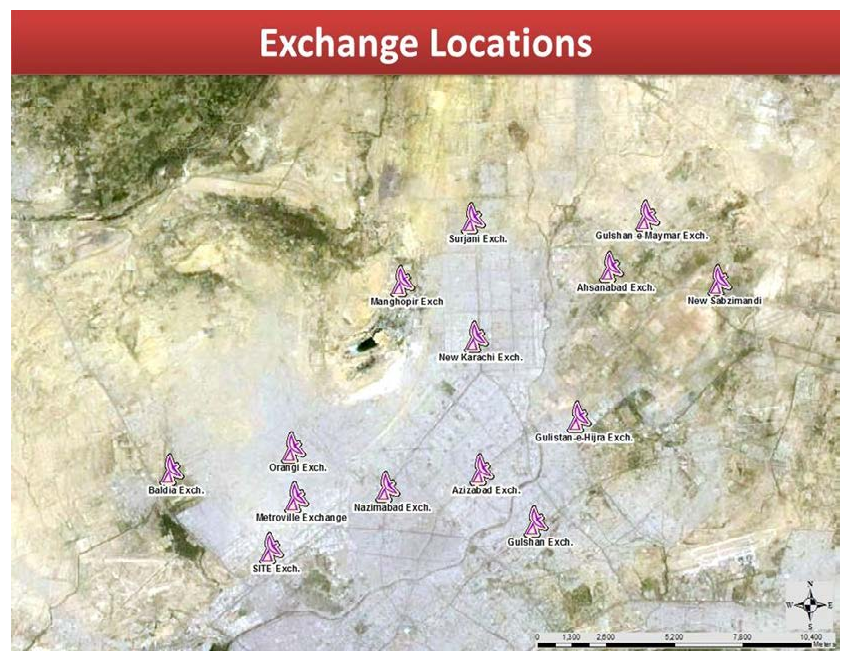

Figure 4: Karachi telecom exchange geographic locations. Source: Author. 
Citation: Khan N (2017) Impacts of Network Efficiency on Number of Customers - A GIS Perspective: Study of Telecom Industry in Karachi. J Telecommun Syst Manage 6: 154. doi: 10.4172/2167-0919.1000154

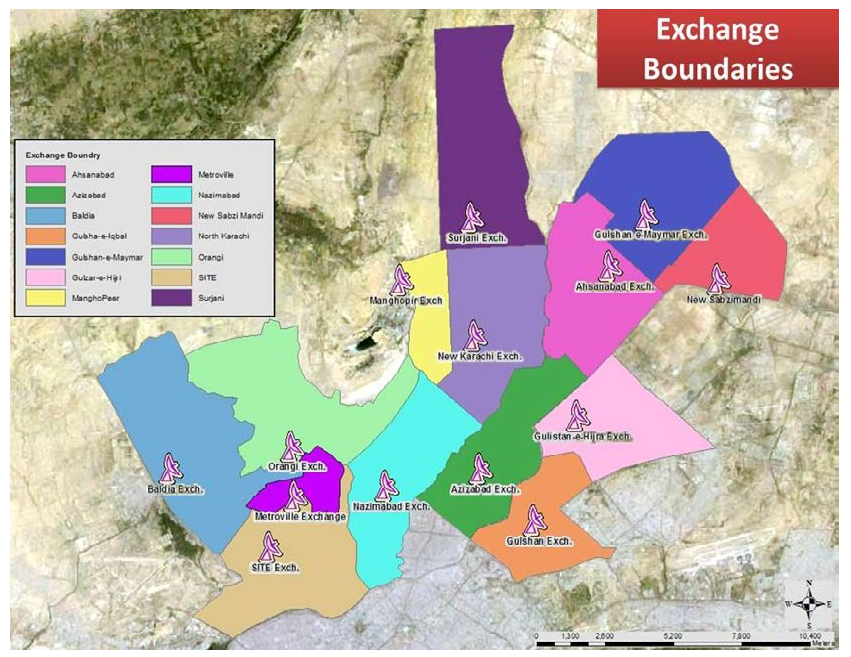

Figure 5: Telecom exchange boundaries. Source: Author.

\begin{tabular}{|c|c|c|c|c|}
\hline \multicolumn{5}{|c|}{ OSP Network 2002-2012 } \\
\hline Exchange Name & Area in Sq. km & OSP Network (2002) Copper Cabinets & ONUs & OSP Network (2012) Copper Cabinets + ONUs \\
\hline Surjani Exchange & 26 & 16 & 0 & 16 \\
\hline North Karachi Exchange & 19 & 99 & 31 & 130 \\
\hline Mango Peer Exchange & 7 & 4 & 1 & 5 \\
\hline Baldia Exchange & 28 & 48 & 2 & 50 \\
\hline Orangi Exchange & 24 & 67 & 6 & 73 \\
\hline SITE Exchange & 23 & 70 & 33 & 103 \\
\hline Nazimabad Exchange & 19 & 170 & 33 & 203 \\
\hline Azizabad Exchange & 18 & 136 & 27 & 163 \\
\hline Gulsha-e-lqbal Exchange & 13 & 111 & 31 & 142 \\
\hline Gulzar-e-Hijri Exchange & 16 & 32 & 27 & 59 \\
\hline Ahsanbad & 21 & 7 & 2 & 9 \\
\hline Metroville Exchange & 5 & 4 & 0 & 4 \\
\hline Gulshan-e-Maymar & 22 & 16 & 6 & 22 \\
\hline New Sabji Mandi & 12 & 6 & 1 & 7 \\
\hline
\end{tabular}

Table 1: OSP installed network in 2002 and 2012 Source: Author.
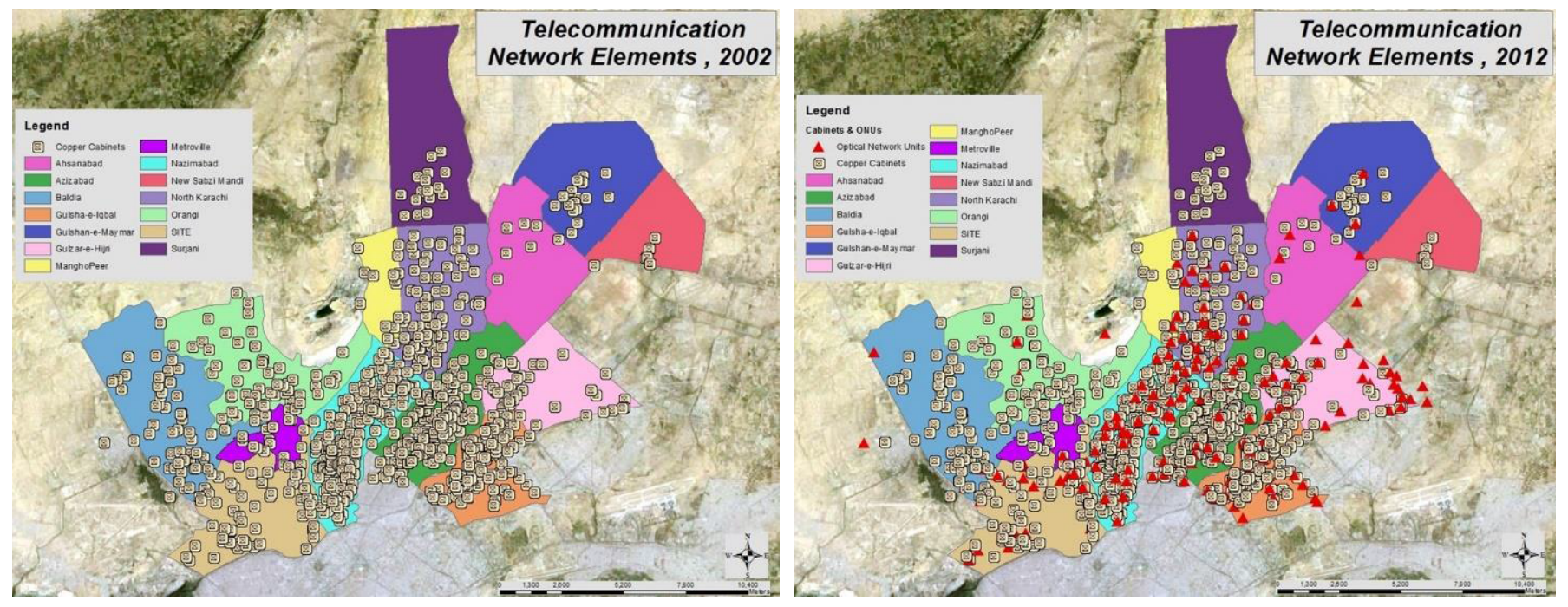

Figure 6: OSP installed network in 2002 and 2012. Source: Author.

approximate $60 \%$ network elements have bad jumpering status that results to create noise or cross talking in the landline connection, similarly $19 \%$ network elements have an average jumpering status which means that if there is an increase in improper jumpering its efficiency starts to decline while $20 \%$ of the installed network, mainly optic network units, have good jumpering status. 
Citation: Khan N (2017) Impacts of Network Efficiency on Number of Customers - A GIS Perspective: Study of Telecom Industry in Karachi. J Telecommun Syst Manage 6: 154. doi: 10.4172/2167-0919.1000154

Page 6 of 7

\begin{tabular}{|c|c|c|c|}
\hline \multicolumn{4}{|c|}{ Landline Customers in 2002 and 2012} \\
\hline Exchange Name & Area in Sq. km & Landline Customers 2002 & Landline Customers 2012 \\
\hline Surjani Exchange & 26 & 3,827 & 2,495 \\
\hline North Karachi Exchange & 19 & 74,849 & 34,306 \\
\hline Mango Peer Exchange & 7 & 658 & 21 \\
\hline Baldia Exchange & 28 & 13,951 & 3,609 \\
\hline Orangi Exchange & 24 & 29,680 & 10,483 \\
\hline SITE Exchange & 23 & 28,660 & 22,417 \\
\hline Nazimabad Exchange & 19 & 77,903 & 57,870 \\
\hline Azizabad Exchange & 18 & 66,024 & 46,368 \\
\hline Gulsha-e-lqbal Exchange & 13 & 59,428 & 40,638 \\
\hline Gulzar-e-Hijri Exchange & 16 & 16,381 & 13,410 \\
\hline Ahsanbad & 21 & 45 & 1,661 \\
\hline Metroville Exchange & 5 & 1,815 & 1,035 \\
\hline Gulshan-e-Maymar & 22 & 1,282 & 3,050 \\
\hline New Sabji Mandi & 12 & 290 & 1,305 \\
\hline
\end{tabular}

Table 2: Landline Customers in 2002 and 2012 Source: Author

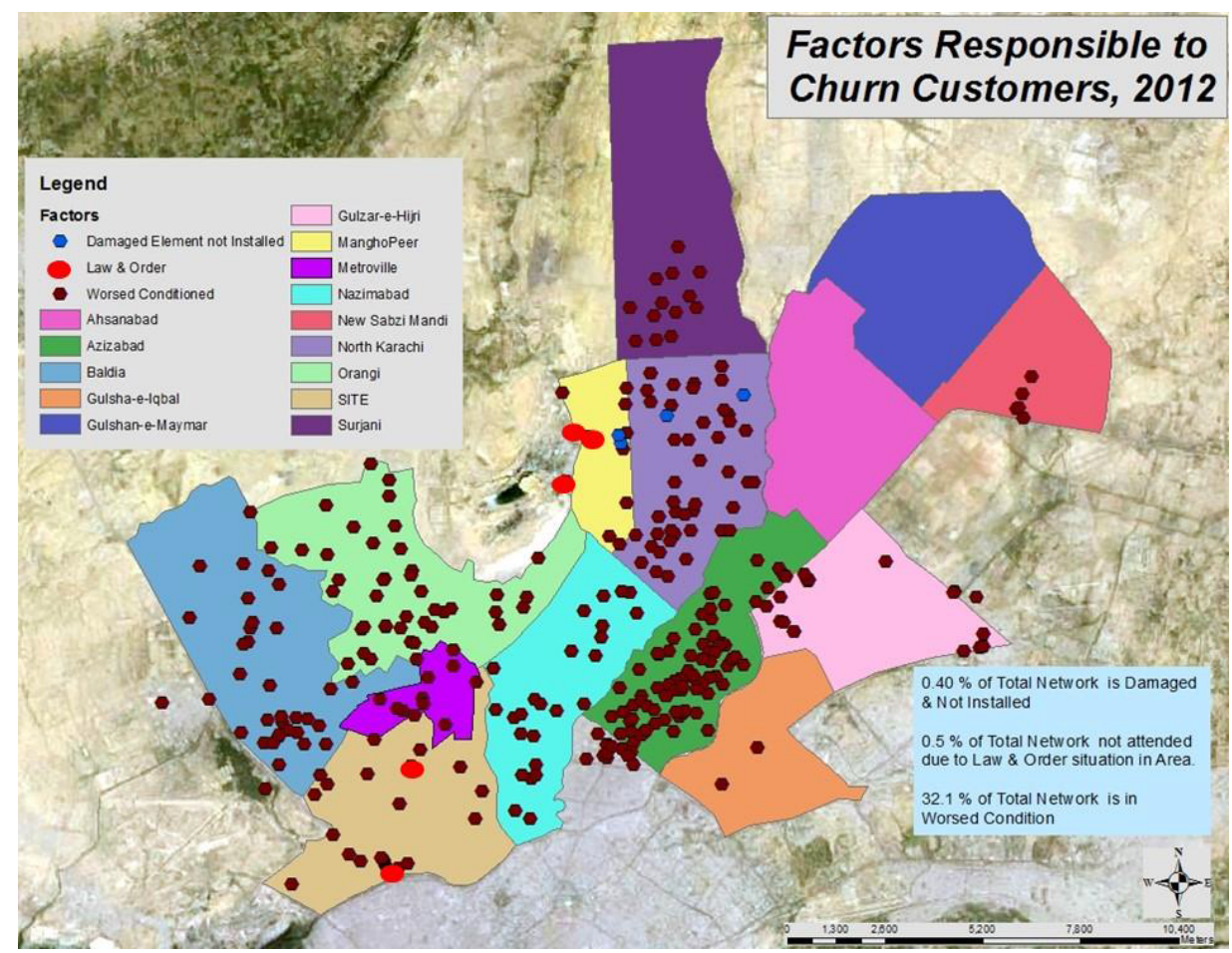

Figure 7: Factors reducing number of customers. Source: Author.

On the other hand if we discuss the physical status or the physical condition of the network element it is also observed that $40 \%$ of the network elements have bad physical condition means that the unit becomes rusty or damaged which is continuously providing interruption in the services as discussed earlier. $42 \%$ network are existing in good conditions while only $17 \%$ of the total network has an average physical condition [9].

It is also noticed that the percentage of bad jumpering status of the total network is much greater than that of the physical condition. If a network element has good physical condition but having bad jumpering status it will create noise or cross talking issues and sometime the landline become dead which results the reducing number of customers [10].

However, there are some other factors that may be affecting the number of customers i.e. faults in primary or secondary cable, accidental cuts off cables remain unattended, consistent fault occurred in main distribution frame etc.

\section{Conclusion}

In this study it is revealed that in the year 2000 and 2002 when there were only copper networks, the number of landline customers were about 3, 74,793 whereas in the year 2012 while there was optical fiber network had also introduced the number of customers were 2, 38,668. It means that number of customers were declining in last decade. To analyze the factors all network elements that installed on ground with their properties are captured during GPS surveys and are stored in geodatabase. Scanning and geo-referencing of maps, field data collection, digitization of network and their attributes integration are the bases on which raster image and calculations are made.

It has been revealed from the study that GIS is such an effective 
Citation: Khan N (2017) Impacts of Network Efficiency on Number of Customers - A GIS Perspective: Study of Telecom Industry in Karachi. J Telecommun Syst Manage 6: 154. doi: 10.4172/2167-0919.1000154

Page 7 of 7

\begin{tabular}{|c|c|c|c|c|c|c|c|}
\hline \multicolumn{8}{|c|}{ Factors Responsible to Interrupt Services } \\
\hline \multirow[t]{2}{*}{ Exchange } & \multicolumn{3}{|c|}{ Jumpering Status } & \multirow[t]{2}{*}{ Total Network Elemennts } & \multicolumn{3}{|c|}{ Physical Status } \\
\hline & Bad & Average & Good & & Bad & Average & Good \\
\hline Ahsanbad & 0 & 0 & 9 & 9 & 1 & 1 & 7 \\
\hline Azizabad & 126 & 23 & 14 & 163 & 101 & 56 & 6 \\
\hline Baldia & 43 & 7 & 0 & 50 & 38 & 5 & 7 \\
\hline Gulshan-e-lqbal & 142 & 0 & 0 & 142 & 1 & 5 & 136 \\
\hline Gulzar-e-Hijri & 21 & 14 & 24 & 59 & 20 & 15 & 24 \\
\hline Manghopir & 4 & 0 & 1 & 5 & 4 & 0 & 1 \\
\hline Gulshan-e-Maymar & 0 & 2 & 2 & 22 & 0 & 1 & 21 \\
\hline Metroville & 3 & 1 & 0 & 4 & 4 & 0 & 0 \\
\hline Nazimabad & 56 & 101 & 46 & 203 & 48 & 63 & 92 \\
\hline New Sabjimandi & 5 & 2 & 0 & 7 & 5 & 0 & 2 \\
\hline North Karachi & 73 & 1 & 52 & 126 & 87 & 0 & 39 \\
\hline Orangi & 63 & 0 & 10 & 73 & 50 & 0 & 23 \\
\hline SITE & 39 & 38 & 26 & 103 & 25 & 23 & 55 \\
\hline Surjani & 15 & 0 & 1 & 16 & 14 & 0 & 2 \\
\hline Grand Total & 5900 & 189 & 203 & 982 & 398 & 169 & 415 \\
\hline Percentage \% & 60.08 & 19.25 & 20.67 & 100 & 40.53 & 17.21 & 42.26 \\
\hline
\end{tabular}

Table 3: Factors responsible to interrupt services Source: Author.

tool that may help the organization to improve the business. Maps that are developed through GIS techniques show that although PTCL has deployed 201 optical network units (ONUs) in the study area and has approximated 785 copper cabinets but still the number of customers is falling. The main reason is that the network required maintenance properly. Factors that are responsible for reducing the customers are as follows:

$60 \%$ of installed network elements had jumpering status very bad which are the basics to provide good services. If jumper wires in the cabinets or in the ONUs are not properly patched or if there is improper jumpering find in network units then definitely it would directly affect the network efficiency and it provide humming and interruption in services which is not acceptable by the customers.

Approximate $40 \%$ network elements had bad or damaged physical status that results to create interruption in providing landline services.

Some copper cabinets are damaged or destroyed during some development works in the city which are not deployed and not attended by concerned departments. The results are that the customers switched to other cellular services. It is also concluded that the area which have been facing law and order situation and staff could not attend their faults, customers are reducing over there.

\section{References}

1. Sui DZ (2004) GIS, Cartography and the "Third Culture": Geographic Imaginations in the Computer Age. The Professional Geographer 56: 62-72.

2. Clarke G, Stillwell J (2003) Applied GIS and Spatial Analysis. John Wiley and Sons: London.

3. Bidgoli $\mathrm{H}$ (2004) The Internet Encyclopedia. John Willey \& Sons: New Jersey vol: 2 .

4. Sengupta S (2007) Geographical Information System Concepts and Business Opportunities. Concept Pub. Co: New Delhi.

5. Armstrong M, Densham PJ (2007) Database organization strategies for spatial decision support systems. International Journal of Geographical Information Systems 4: 3-20.

6. Attaa A (2011) Financial Tale of PTCL.

7. Godin L (2001) GIS in Telecommunication. ESRI Press: Redlands. Google Earth Inc.

8. Kazmi JH (2007) Role of Geo-Informatics in Scientific Development: A Review of Pakistani Experience in Space Sciences. Karachi University Journal of Science 35: 39-44.
9. Taylor K, Walker G, Abel D (2010) A framework for model integration in spatial decision support systems. International Journal of Geographical Information Science 13: 533-555.

10. Tomlinson FR (2006) Thinking About GIS: Geographic Information System Planning for Managers, ESRI Press: Redland. 